\title{
The Prevalence of and Factors Contributing to Assessment Malpractice at the National University of Lesotho
}

\author{
Pulane J. Lefoka ${ }^{1}$ \\ ${ }^{1}$ Centre for Teaching and Learning, National University of Lesotho, Lesotho \\ Correspondence: Pulane J. Lefoka, Centre for Teaching and Learning, National University of Lesotho, Lesotho
}

Received: August 6, 2020; Accepted: August 18, 2020; Published: August 18, 2020

The research was financed by the National University of Lesotho.

\begin{abstract}
This article draws its content from a study that investigated the prevalence of and factors contributing to assessment malpractice by students at the National University of Lesotho (NUL) during assessment activities. The study was carried out in response to a general outcry regarding malpractices that abound in all forms of assessments. The main objectives of the study were to investigate the following: the extent to which examination malpractice during assessment activities was a problem at the NUL. Data was collected through the use of questionnaires. Both quantitative and qualitative data were captured and analysed using computer programmes. The study has revealed that assessment malpractice is prevalent at the National University of Lesotho and that a number of factors are contributory to the situation.
\end{abstract}

Keywords: assessment, malpractice, cheating, contributory factors, prevalent, investigate

\section{Introduction}

\section{Introduction of the Problem}

Teaching and learning institutions use a variety of assessment methods to assess student performance. Examinations in educational institutions, are used for specific purposes including determine promotion of students into the next level or dismissing them if they perform poorly. However, institutions encounter problems in situations where students engage in malpractice. Reports on cheating in examinations in various parts of the world and at various levels of education systems indicate that examination malpractice in any form of assessment is a serious problem. It also comes to light that cheating is on the increase especially at various levels of education systems including universities (Nenty \& Tsheko, 2005, Teferra, 2001).

The study carried out at NUL established the extent to which students are involved in malpractice during the various forms of assessments in which they are involved. These forms of assessing students include tests, projects, assignments and examinations. Incidents of assessment malpractice at NUL have been reported in the past and continue to be reported by invigilators in particular. A compilation of invigilators' reports submitted to the relevant units of the University indicates that there are numerous problems which impinge on assessment malpractice, especially during examinations.

In particular, the invigilators' reports make reference to certain issues and habits or practices that contribute to assessment malpractices, especially during the undertaking of examination activities. Some of these are the status of examination halls; the use of toilet facilities during examination sessions; types of materials that students bring to the examination halls; personnel in charge of administration of examinations at all levels; printing errors; and non-compliance with regulations. However, regardless of the reported number of malpractice cases, the National University of Lesotho has never undertaken a study that might inform it about assessment malpractice and factors that contribute to the situation.

With what has been said thus far, the objectives of the study, therefore, were to investigate the extent to which assessment malpractice is a problem at NUL taking into consideration factors such as administrative-related, student-related, staff-related, test-related and society-related factors; and the extent to which gender has an influence on cheating during assessment activities and whether or not the University's regulations have any influence on cheating during assessment activities. These objectives were adapted from Brimble and Stevensonclark (2005) and Nenty and Tsheko (2005). 
The study was undertaken to address an institutional problem which relates to social matters. Students some of whom have passed examinations through malpractice entre the public space not qualified to serve society. This means the institutions of higher learning is sending out to the society a low calibre of products. The study ought to be consistently undertaken to ensure that in the final analysis the institution gives back to the society quality products. Therefore, this type of study needs to be undertaken every three years to ensure that malpractice is uprooted.

The literature points to Research on malpractice that has been undertaken in various institutions by researchers such as Nenty \& Tsheko, (2003); Stevensonclarke, (2003); Singh, (1984) who indicate that there is ample literature based on research undertaken in the area. These researchers motivated the efforts to research factors contributing to malpractice at the National University of Lesotho. The literature indicates that malpractice is a common problem in higher education. To Adelaku and Lawal (2008), "there are consequential effects of examination malpractice which include erosion of confidence in the education system; loss of credibility in the education assessment; examination agencies discredited, leading to a loss of confidence in the certificates that are issued by the agencies; the rising cost of conducting examinations when massive leakage is established; cancellation of results causing undue suffering to innocent students; increased corruption levels in a society; and eventual retardation of national development" (p.62)

\section{Methodologically}

The study gathered data from students in faculties and the Institute of Extra Mural Studies, staff and personnel in administration as well as external invigilators. Given the assumption that assessment malpractice is a problem at the National University of Lesotho, all faculties and teaching institutes participated in the study. That being the case, the population of the study consisted of students, lecturers and administrators at faculty and university levels. A systematic sample of students was used across the various faculties and institutes. A similar approach was used for the survey of teaching staff, but some faculty and relevant examination administrative staff members were selected in a purposive manner for interviewing. The offices of deans, those of the Vice-Chancellor, the Pro ViceChancellor and the University Registrar were also included in interviews.

Research information for the study was collected through three methods. These methods are review and analysis of documents such as external examiners' reports, survey by questionnaire administered to the various groups, and structured interviews.

\section{Results}

It was absolutely crucial to find the students' understanding of the concept under investigation. Hence, in this findings section of the paper, one of the issues presented is the students' understanding of the various terms used whenever addressing assessment malpractice. During the study, the students were asked to select one statement which they thought meant the same as the term "academic malpractice" from a list of four. Table 1 shows the breakdown of responses.

Table 1. Students' Understanding of the Concept Academic Malpractice

\begin{tabular}{lll}
\hline Statement of meaning & Frequency & \% \\
\hline Academic dishonesty & 422 & 49.9 \\
Copying & 284 & 33.6 \\
Academic misconduct & 72 & 8.5 \\
Academic malpractice & 56 & 6.6 \\
Other (not specified) & 11 & 1.3 \\
Total responses & 845 & 100.0 \\
\hline
\end{tabular}

Half of the students preferred the term "academic dishonesty". Nevertheless, the fact that one-third equated assessment malpractice with "copying" suggests that this is the most common form in their academic context.

\subsection{Terminology Used}

Different meanings of cheating abound in the world of academics. The University of Botswana (2007) describes cheating as using or attempting to use unauthorised materials, information, or study aids in any academic work. Examples include (University of Botswana, 2007, p. 3)

obtaining tests, assignments and examination questions by any means; having in one's possession or using any unauthorized material in assessment or examinations; copying or attempting to copy from the work of 
another student; submitting the same piece of work in more than one course; submitting a 'take home' piece of academic work that has been written in full or in part by someone else.

Over and above describing malpractice, the University of Botswana considers the following terms as also describing academic dishonesty: falsification and fabrication, collusion, plagiarism and academic fraud. This University concludes that any particular form of cheating is also regarded as an example of misconduct in examinations under its policy on academic honesty for students (University of Botswana, 2007).

The National University of Lesotho students, besides being familiar with the numerous terms used worldwide to describe assessment malpractice behaviour, indicated that they use mainly their own terminology that they are familiar with. Most of the terms in Table 2 relate to war or are of a weaponry nature, with the exception of a few phrases which suggest preparedness and bravery. Some of the phrases are Sesotho (local language) proverbs, which are far off in meaning to assessment malpractice. These proverbs have been cunningly distorted to suit acts of cheating that students engage in.

Table 2. Terminology and Concepts used by Students

\begin{tabular}{|c|c|c|}
\hline $\begin{array}{l}\text { Terms in } \\
\text { Sesotho/Words and } \\
\text { Phrases }\end{array}$ & Translation & Interpretation \\
\hline Koto & Knobkerrie & $\begin{array}{l}\text { A piece of paper on which students have } \\
\text { written notes that they could use in an } \\
\text { examination. }\end{array}$ \\
\hline Koantsanyane & A spear-like weapon & $\begin{array}{l}\text { Also, a piece of paper on which students have } \\
\text { written notes that they could use in an } \\
\text { examination. }\end{array}$ \\
\hline Referencing & $\begin{array}{l}\text { Working out details of references in } \\
\text { an academic paper }\end{array}$ & $\begin{array}{l}\text { Colleague to act as reference, or piece of } \\
\text { written material to act as reference }\end{array}$ \\
\hline Giraffeing & Acting like a giraffe & $\begin{array}{l}\text { Implying stretching a neck in order to see from } \\
\text { a distance - could be from own notes displayed } \\
\text { in a manner known to the student or copying } \\
\text { from another student's work }\end{array}$ \\
\hline Morathatha & $\begin{array}{l}\text { A massive deadly rifle which } \\
\text { releases several bullets at a time with } \\
\text { a thunderous sound }\end{array}$ & $\begin{array}{l}\text { Implies bringing more material, instead of a } \\
\text { piece of paper. This could be a page or pages }\end{array}$ \\
\hline $\begin{array}{l}\text { AK47 } \quad \text { (Russian } \\
\text { made) }\end{array}$ & Same as Morathatha & Also implies more materials \\
\hline Open book & & Borrowed from an open book test \\
\hline Dubbing & $\begin{array}{l}\text { Copying music from one disc to the } \\
\text { other }\end{array}$ & $\begin{array}{l}\text { Reproduce materials as is from class or notes } \\
\text { takes in class }\end{array}$ \\
\hline Re ja Sehoete & We eat a carrot & $\begin{array}{l}\text { Implies that a student's sight is sharp because } \\
\text { they eat carrots/able to read very small } \\
\text { handwriting from the pieces of paper in which } \\
\text { they have written notes }\end{array}$ \\
\hline Lerumo la Koebe & Three-pronged deadly spear & $\begin{array}{l}\text { No matter how high the cost of copying or } \\
\text { cheating }\end{array}$ \\
\hline \multicolumn{3}{|l|}{ Phrases } \\
\hline $\begin{array}{l}\text { Lekanyane ho phela } \\
\text { le liretse (Sesotho } \\
\text { Proverb) }\end{array}$ & One has to work hard to reap success & They will pass only if they cheat \\
\hline $\begin{array}{l}\text { Khomo ha li na mo } \\
\text { tloha pele (Sesotho } \\
\text { Proverb) }\end{array}$ & $\begin{array}{l}\text { Even if one missed out on a head } \\
\text { start, one can still succeed through } \\
\text { hard work }\end{array}$ & \\
\hline $\begin{array}{l}\text { Khomo li hana o li } \\
\text { roballa teleha } \\
\text { (Sesotho Proverb) }\end{array}$ & $\begin{array}{l}\text { Success/reward does not come easy- } \\
\text { one has to struggle for a while }\end{array}$ & $\begin{array}{l}\text { It does not matter how hard one studies; others } \\
\text { will still catch up with them in the } \\
\text { examinations by cheating. Even those who are }\end{array}$ \\
\hline
\end{tabular}


Ea lla koto ea khutla naha (political slogan)

Distinction, first class, second class and NMDS funding

Sefelekoane beta pelo

o kene koetseng

(Sesotho Proverb)

Monna ha a sie

lihlomo ha a ea

ntoeng (Sesotho

Proverb)
An old political slogan by the BCP party, which was popularly used during the peak of political activity in Lesotho during the struggle for independence. It essentially made reference to land that Lesotho historically lost to the Republic of South Africa

Be brave and face the odds

A man does not go to war unarmed, i.e. he has to be fully armed

not studying hard will still pass through foul means - essence of time

Unless you bring a piece of paper, you will forfeit getting a pass in an examination and consequently receiving a scholarship offered by the National Manpower Development Secretariat (NMDS)

Used in a situation where a student finds that an examination is so difficult that he has to be courageous to use cheating strategies OR "if you can't beat them join them"

Students should not leave behind prepared materials when going into examination halls/rooms

Most importantly, these words imply taking risks and being prepared to do so. Summerson and Farley (2009), in their article on "predicators of college achievement", refer to Farley (1991), who writes on thrill seeking, this being a personality trait in people who are risk-takers and are motivated by variety, novelty, intensity and uncertainty. However, in these authors' context, thrill-seeking students would be those who thrive in an academic environment where there is a high level of stimulation when compared to their opposites who do not need as much stimulation. It would seem that NUL students who are involved in academic malpractice are thrill seekers of a different type. They are thrilled by achieving academic excellence by foul means.

The varied terminology used seems to confirm what the literature suggests, which is that a number of strategies are employed whenever students are involved in assessment malpractice actions. There are serious implications for the current status in which students seem to perfect their skills in academic dishonesty, as opposed to learning or perfecting their skills in attaining knowledge and skills during their studies at the University. Therefore, the use of these terms implies that students have strategies for ensuring that they are never caught cheating. This view is confirmed by Singh (1984) who found that students tend to establish that those who cheat are hardly ever caught.

Studying the cases of students who engage in assessment malpractice confirms that it is difficult to get caught and that even when a student has been caught cheating, little is done about his or her future in academic arenas. A sample of 20 cases of students who were caught cheating during the final examination of the academic year 2008/2009 at the National University of Lesotho clearly illustrated the point. Seventeen out of the 20 students who copied pleaded guilty. They all brought notes on various coloured papers including the green papers used by the University for printing examinations papers. They, except in one case where a student had photocopied material, entered the examination room with these papers, having used very small handwriting to write notes. A student who argued that he had not brought the paper into the examination room deliberately, explained:

Usually when I read, I write all my notes on a page and use a technique called photographic memory, which always aids me in tests because I make pictures of all pages in my mind. On this day, although I woke up early, that is at dawn to study, I wrote all the notes in two pages and started picture photographing it; I read the pages about 50 times, as that aid to have them implemented in my brain.

\subsection{Extent to which Assessment Malpractice is a Problem at NUL}

Both the staff and the students who participated in the study were asked to indicate the extent to which they thought examination malpractice was a problem at NUL, selecting one of the alternatives: "not serious", "serious", "very serious" and "extremely serious". While a majority of each of the groups that responded to the question felt assessment malpractice was a problem, it would seem that the students, more than the staff, think that cheating is an extremely serious problem. Staff members were further asked to explain why they thought assessment malpractice was a serious problem at NUL. They said it was serious because, in every examination, at all levels of study and in other forms of assessment, students were caught cheating - students "do it at any cost". They thought it was so rampant that some students considered it normal to engage in assessment malpractice activities. 
Staff members were further asked about the prevalence of cheating in assessment activities among NUL students. Only four (9\%) of the respondents thought cheating was not widespread. These respondents mentioned that cases of assessment malpractice that are usually reported are few in relation to the huge number of students who may sit for an examination or write an assignment at one given time. However, $60 \%$ of the staff members said that assessment malpractice was a widespread phenomenon at NUL. A variety of reasons were given to justify this impression. It was mentioned that every year, in every examination and across all faculties, students are caught cheating. Nonetheless, some staff members expressed the view that cheating is more widespread in faculties or departments where there are many students. It was revealed that staff always report finding pieces of notes strewn on the examination hall floor or in toilets. The pieces of paper are said to be called "koantsanyane"/spear. Staff members also said it is not uncommon to find two or more remarkably similar answers in a given test or assignment. Students often justify this by saying answers may be similar because they discuss in groups.

Be that as it may, the invigilators' reports, prepared after every examination, seemed to support the view that assessment malpractice is prevalent at NUL. For example, they indicated that while no one was ever caught copying in a toilet setting, students' note papers were found thrown in the toilets with pieces torn off, which makes one suspect that those were the relevant materials.

\subsection{Factors Contributing to Cheating during Assessment Activities}

The study has revealed that the following factors contribute to assessment malpractices: administration, staff and student-related; course-related; and assessment and society-related factors.

\subsection{Administrative-Related Factors}

The study has revealed that a number of administrative-related factors contribute to examination malpractice. These include insufficient infrastructure, unacceptable staff practices, admitting a large number of students, and inadequate university regulations. Examination halls are too small for large numbers of students and are therefore congested, a situation which makes it easy for examinees to engage in malpractice activities. Sitting arrangements and having different examinations of varying programmes written in the same hall at the same time also encourages the practice of copying.

The handling of assessment materials, particularly examination papers, involves various people with different tasks. Examination papers, although typed centrally by different secretarial staff every year, are handled by too many people. This involves the typing of examinations from departments and faculties to their retyping in the Academic Office and ultimately their printing. It is clear that part of the problem results from work undertaken in the University Printing Unit. For example, examination papers are sometimes wrongly collated by personnel in the University Printing Unit.

The work of invigilators as personnel charged with the responsibility of supervising examinations is made difficult by the large population of students who sit for examinations at one time. One of the requirements is that students must be thoroughly checked prior to entering examination halls. However, there are some discrepancies. Examinees enter examination halls with numerous documents that are not authenticated. This is regarded as one of the major administrative loopholes which perpetuate assessment malpractice.

The tendency for lack of originality and poor referencing of materials used for research projects and assignments is linked to inadequate modern technology infrastructure. This is said to affect the rate at which students can access the latest research-based information. Students and staff are in unison regarding the inadequacy of information access, which is much needed for strengthening intellectual development.

There was a feeling that factors such as the inadequate number of invigilators at any given time, also contribute to cheating, a view expressed by $16(35 \%)$ of the staff members. The reluctance of lecturers to invigilate during examinations was cited as the major contributor to poor invigilation. Some respondents said that this gave rise to "too many students versus too few invigilators". There was also a concern that was raised about too many students crowding small examination halls. Twelve (27\%) of the staff members felt that students do not have adequate space between them; hence, it becomes easy for them to organise their assessment malpractice activities. Again, five $(11 \%)$ of the staff members felt that the perpetuation of these unacceptable circumstances leads to leniency and reluctance to deal harshly with perpetrators. At times, wrong question papers end up in the examination halls, only to be discovered when students have to write, thus encouraging those who have seen the wrong paper to devise ways and means of cheating in the same examination when its proper time is due.

The same question was addressed to the students. However, in their case, the question was not simply open-ended: students were given 17 prepared items to consider. They were asked to indicate, for each item, whether they 
considered it to be "not common", "common", "very common" or "extremely common" as a factor contributing to cheating.

For practical purposes, the most fundamental distinctions are between those who are rating a given item as "not common" and those rating it as "common" or above that rating. It may be inferred from the statistics that a majority of NUL students consider the following factors:
a) sneaking in written material and using electronic materials;
b) impersonating a student in examinations;
c) allowing others to copy from one's work;
d) copying from others during examinations;
e) giving answers by signals or codes;
f) continuing to write after a test has finished;
g) gaining unauthorised access to material;
h) paying another person to complete a test;
i) working together instead of individually;
j) writing an assignment for someone else;
k) copying directly without another student's consent;
1) copying directly from books or periodicals with no quotes;
m) not reporting fellow students who cheat;
n) copying directly from other students with consent;
o) paraphrasing information without referencing; and
p) requesting special consideration for deferment of examination

to be common or above common, with four exceptions. Three of these: using electronic materials, impersonating a student in examinations, and continuing to write after a test has finished, are rated by a clear majority as not common. Furthermore, the $t$ statistics for the differences between the proportions of "not common" and 0.5 are all significant $(\mathrm{t}=4.57,5.59$ and 2.86 respectively). In the case of "gaining unauthorised access to material", the opinion is divided, as the $t$ statistic is not significant $(t=0.70$ for the difference between the "common or above" proportion and 0.5 ).

Other points to note are that sneaking written material into tests and examination rooms, and copying from others during examinations were considered particularly prevalent. Many students are apparently willing to allow others to copy from them, hence the use of the term Giraffeing and are unwilling to report cheaters even if they do not cheat themselves. These responses help to show the extent to which cheating has become part of the student culture. The responses to the last item suggest that the University authorities are sometimes duped into allowing deferment of examinations to students who have no valid grounds for it.

\subsection{Staff-Related Factors}

It has been revealed that owing to their high level of absenteeism from examination halls and lackadaisical approach to their work, lecturers also contribute to the prevalence of malpractice at NUL. To a large extent, students, more than staff, feel that once students are in an examination hall, they should be left alone to get on with the examination task. Still, the tendency for lecturers is to make announcements that are intended to correct errors or make adjustments on examination papers. What seems to be lacking is paying more attention to such matters outside and prior to the actual examination sitting. This is also in keeping with the feeling that if lecturers were vigilant and committed to more organised and monitored operations, then errors would not have to be corrected in the examination halls.

Asked to give their opinion on staff practices that contribute to cheating, $16(36 \%)$ of the staff members indicated that staff and invigilators do not pay attention to activities that could easily lead to cheating, while 14 (31\%) indicated that the teaching staff lack assessment techniques. Some staff members mentioned poor teaching methods as a factor, and others indicated that methods used to approach students who have been caught cheating contributed to the problem.

Commenting on assessment practices, the staff respondents mentioned the following additional factors: poor timing of tests; giving of irrelevant examinations; asking the same questions for both the internal test and the final 
examination. Other factors included giving the same examination year after year; using a style of asking questions that is likely to encourage assessment malpractice; befriending printing staff; delegating the responsibility of tests invigilation to one's own secretary; and giving students what is popularly known as "scope". Some staff members had this to say about what is popularly known as scope:

It involves] providing the students with specifics of content when providing them with an examination scope. The practice of "scope" has a way of encouraging copying if students are not familiar with the topic. Providing students with the scope of the examination and giving students possible examination questions.

A view was expressed that some of the lecturers may not even be aware that giving a "scope" is leading students to assessment malpractice. Other views indicate that some male lecturers befriend female students to the extent that such students tend to have access to an upcoming examination paper. With regard to teaching methods, some respondents had this to say: "Not all lecturers/teaching staff members are trained on how to teach, how to approach students, how to prepare for teaching, how to interact with students and how to behave in class".

Views on invigilators' practice indicate that some of the lecturers frequently absent themselves from an examination room and/or leave students on their own. Moreover, these lecturers are not vigilant, to the extent of occupying themselves with other activities instead of watching students who are likely to cheat. Also, there are inconsistencies in the way they undertake their task. An example was given that some are very strict with the use of cellular phones while others are relaxed about it. However, there are opposing views as well. It was revealed that invigilators are overloaded. The reasons advanced for this view are that the number of examinees increases every year, yet that of invigilators is not revised; the number of invigilators is small to the extent that in situations where students send them around to locate their lecturers, some students use the same time to engage in cheating.

Another view is that external examiners compile reports every year, in which they allude to the fact that the assessment malpractice problem is escalating but that the University authorities have never taken these reports seriously. This assumption was based on the observation that the reports have never been used to inform major deliberations on how the problem of cheating can be tackled, even though these reports articulate the problems encountered and propose possible solutions. For example, one invigilator wrote, "invigilation of examinations at the University continues to present more and more experiences, surprises and new incidents every year". Regarding electricity blackouts, the invigilator wrote, "As the examinations were about to start, electricity went off and was not there throughout the morning session of the examinations".

She recommended:

The idea of a standby facility or prior arrangement with those concerned, like the Lesotho Electricity Corporation (LEC), that there would be examinations running on the set days, [should] be explored well ahead of the time of examinations. University examinations, or any other operations for that matter, should not be exposed to such hazards and interruptions" (Unpublished invigilators' reports).

The students who responded to this question seem to share similar views to those of the lecturers. They made reference to teaching techniques, which entail poor approaches towards imparting knowledge, dictating notes and rushing to cover the course content. They also indicated as practices that contribute to examination malpractice, the fact that lecturers tend to favour some students and discriminate against others to the extent of having conflicts with those that they discriminate against - a practice that in their view is highly unprofessional.

Respondents, particularly the staff, indicated that facilities which are in place to assist with photocopying but which are operated by staff can be a contributory factor to examination malpractice. As indicated earlier, cases where papers are wrongly collated are common. The case in point is that of the History examination paper, where one side of the paper was a History examination and the other was an English examination. It was noted that while invigilators may collect papers upon realising such a mistake, it is possible that due to the large population of students who sit for an examination against a small number of invigilators, students may hide such papers to either use them later, distribute to friends or even sell to colleagues. This form of negligence or irresponsibility, which is said to be demonstrated by both lecturers who never ensure that their papers are well collated and the printing staff, is regarded as one of the practices that could contribute to leakage of examination papers and consequently to malpractice.

Other staff-related factors include a course lecturer being absent on a day that his/her examination paper is being written. This practice is said to lead to chaos when invigilators have to locate such lecturers and leave the examination hall to an even smaller number of invigilators. It was revealed that students tend to take advantage of any situation that presents itself to engage in malpractice activities. 


\subsection{Course-related Factors that Contribute to Cheating}

The study has revealed that there are some course-related factors which contribute to assessment malpractice. Students register in courses that they know have a high failure rate. Consequently, they tend to copy more in such courses. This tendency is attributed to a psychological connotation in that students imagine that it is a difficult course.

Both the staff and students were asked to indicate, by giving a rating on a five-point scale, the extent to which they agreed with the following statements: students are more likely to cheat in a course that has a high failure rate history; students are more likely to cheat in answering objective questions; knowledge of lecturers' questions contributes to cheating; and cheating is more prevalent in certain courses, particularly those in Science and Agriculture - these are courses that use laboratories.

Some respondents supported the survey statements reported in the preceding paragraph as follows: where a course has a high failure rate history, such a course has psychological connotations in students' minds - for them, it is a difficult course in which they are more likely to cheat; also, students are likely to cheat in answering objective questions owing to the regulation that for the first 15 minutes of the examination period, students are given an opportunity to read an examination paper and jot down points. This "blanket regulation" is not necessary for objective tests, but students take this opportunity to jot points down with the purpose of asking others for help where they have problems. The jotting down of points is understood to be relevant only to those students who are supposed to respond to an essay type of question; students tend to cheat in courses that involve figures. They tend to write formulas on wrapping paper for sweets or on papers hidden in calculators.

Regarding the extent to which students copy in a test or examination that involves objective type of questions, it would seem that respondents do not consider this to be much of a contributory factor.

The study has revealed that knowledge of a lecturer's style of asking questions has an influence on assessment malpractice. Students tend to anticipate how possible types of questions could be asked in tests or examinations.

It would seem that while cheating is not so much prevalent in certain courses, students copy across all courses. Having said that, the qualitative data seems to suggest that assessment malpractice is more prevalent in courses that involve figures.

Staff members were asked to give their perceptions regarding why students cheat during assessment activities. Asked to give reasons why students cheat, half $(50 \%)$ of the staff expressed the view, "students do not want to fail".

It has been established that a number of assessment-related factors contribute to assessment malpractice. These include the difficulty level of questions, knowledge of possible questions to be asked, questions that do not correspond to the course outline, reference materials that are not reflected on the course outline, and poorly constructed questions.

Respondents were asked to indicate the level to which they agreed with statements on assessment-related factors that contribute to cheating during examinations and to give reasons for agreeing. The factors for which they had to indicate the extent to which they agreed are as follows: the level of difficulty of questions - students may be more likely to cheat if questions are difficult; prior knowledge of examination questions - students who somehow discover the likely form and content of questions may be more likely to carry notes for the purpose of copying; questions that do not correspond to the course outline - such questions may encourage students to cheat as a survival strategy; questions for which reference material is not listed in the course outline can also affect students' writing in the examinations as well as low level type of questions - questions that require little more than simply recalling information make it easier to cheat by copying and so may encourage such behaviour.

In conclusion, there are three main points to note. First, the factor of questions not corresponding to the course outline attracted high or very high agreement from a clear majority of students, the sample proportion being significantly above half $(t=3.35)$. Secondly, prior knowledge of questions, as a factor, attracted high or very high agreement from half of the students and a large minority of the staff. Thirdly, none of the other items attracted high levels of agreement. These points are consistent with what has been said earlier about the poor assessment skills of some lecturers and about the practice of giving a "scope" to students before an examination. Nevertheless, whether examination questions are relatively easy or difficult may not make much difference to the likelihood of cheating. 


\subsection{Society-Related Factors}

There are society-related factors which put too much pressure on students. Students enter university with good grades, and society tends to expect them to maintain a high level of performance regardless of university education demands. The majority of students who enrol with NUL are sponsored by the Government of Lesotho. Such students have to pass examinations and proceed into the next year of study in order to continue to be sponsored by Government. In addition, those students who plan to pursue postgraduate studies have to perform very well in their undergraduate programmes. These society-related factors have been found to also contribute to cheating.

In conclusion, a number of factors are confirmed as contributing to cheating during assessment activities. They relate to administration, staff, students, courses, assessment and the wider society. The study has revealed that a number of administrative factors contribute to examination malpractice. Most importantly, the University itself does not have in place a clear policy on academic malpractice.

\subsection{Extent to which Gender has an Influence on Assessment Malpractice}

A question on the gender that copies most had been addressed both with the staff and with the students who participated in the study. The opinions given on this issue are summarised in Table 3.

Table 3. Which Gender Copies Most: Staff and Student Responses

\begin{tabular}{|c|c|c|c|c|}
\hline \multirow[t]{2}{*}{ Which gender } & \multicolumn{2}{|c|}{ Staff } & \multicolumn{2}{|c|}{ Students } \\
\hline & Frequency & Per cent & Frequency & Per cent \\
\hline Both & 26 & 68.4 & 499 & 59.2 \\
\hline Female & 8 & 21.1 & 133 & 15.8 \\
\hline Male & 1 & 2.6 & 210 & 24.9 \\
\hline Do not know & 3 & 7.9 & 1 & 0.1 \\
\hline Total responses & 38 & 100 & 843 & 100 \\
\hline
\end{tabular}

As reflected on the Table 3, the consensus among both staff and students is that the rate of examination malpractice is similar for male and female students. Two hundred and ten of the students who thought male and female students cheated equally said cheating was not gender-related. They said both male and female students had the same fears and insecurities towards examinations and tests, and that both male and female students were exposed to the same conditions and situations during examinations. Their motives for cheating are the same. The common aim and goal are to pass and proceed to the next year or to complete studies at NUL. The difference is the manner in which the genders do it. Male students are braver and do not fear to be caught. Female students are smarter and more discrete in the way they cheat. They said assessment malpractice at NUL has become a "norm and a culture": people just cheat; it does not matter whether one is male or female.

Staff also felt that both genders copy at the same rate because they are mixed in their discussion groups. It is in group discussions where members plan cheating strategies for tests and examinations. Group members sit together in examination rooms so that they may help one another.

Staff members who felt that both male and female students cheat also said that cheating was not gender-related. They said both male and female students had equal chances of cheating. They said students behaved in the same way during examinations and tests; they panic irrespective of whether they are male or female. If they are not prepared for the examination or test, they will seek other means of passing - including cheating.

Students who thought male students copied more than female students said males were brave; others said they did not give themselves time to read but spent their time at the bar drinking and/or using drugs or spent time at the football pitch. Others said most male students believed that cheating proves that one is a man; it is therefore a matter of peer pressure more than anything else. Male students are high risk-takers and can do anything to pass, so they say.

Students who thought female students copied more than male students said it was because female students were "smart" when they copied. They copy in toilets, and the way in which they dress permits them to hide notes in their clothes, especially pregnant women, and invigilators do not search female students thoroughly. They further said that female students took advantage of the winter period to wear more clothes. These students said female students were not usually suspected of copying, so they did it easily because invigilators did not pay much attention to them. They also said that because female students are vulnerable, they tend to have relationships with male 
lecturers and want to please them. The students said that female students are sensitive to what is said about their studies and will go to extremes to make sure that they pass examinations.

Two of the three invigilators in particular - as ones who actually catch out the culprits - also thought that the rate of copying for male and female students was the same, but the manner in which copying was done was rather different. The invigilators also indicated that female students do it "tidily" and are more careful, while male students are "arrogant and careless".

It is concluded that this study has revealed that both male and female students get involved in assessment malpractice. This means that academic dishonesty is not related to gender. The difference is with regard to their strategies of cheating, in that the female students were seen to be discrete in their methods of cheating, while the male students were not. That both groups are involved is based on the understanding that they have a common desire, that of passing tests and examinations.

\subsection{Extent to which Measures Taken are Stringent Enough}

When asked to what extent measures taken to discourage students from cheating are stringent, $60 \%$ of the staff members felt they were not stringent enough, $24 \%$ said they were stringent enough, while $11 \%$ felt these measures were not stringent at all. The first group feels authorities are doing their best to address the situation $-\mathrm{a}$ view opposed by the latter groups, whose view is based mainly on the frequency of recurring incidents of cheating. This serves to indicate the inadequacy of punitive measures.

\section{Discussion}

The finding that cheating is a serious problem facing institutions of higher learning has been established by a number of researchers (Nenty \& Tsheko, 2003; Stevensonclarke, 2003; Singh, 1984). The finding on the extent to which cheating is a problem at NUL is strongly supported by documentation of cases reported by the invigilators during external examinations.

The study has revealed that a number of factors are always at play during most assessment activities. These factors directly or indirectly contribute to assessment malpractice by students of the National University of Lesotho. Lecturers do or say things, consciously or unconsciously, which influence students' cheating. Students, on the other hand, engage in behaviours which are aimed at helping them cheat in assessment activities for a number of reasons justifiable only to themselves. The University itself cannot be absolved from contributing to cheating in one way or another. Lack of clear policy on examinations, inadequate infrastructure and many other administrative shortcomings have a direct or indirect bearing on malpractice by students in assessment activities. Staff habits and practices, which are influenced by the lack of clarity of regulations governing staff behaviour, have also been found to contribute to cheating by students.

A fact that has strongly emerged from this study is that assessment malpractice is so widespread that students at NUL do it "at all costs" as some staff members have pointed out. It has become so common that in the mind of some students, it is normal to cheat. It would seem that while students do understand what cheating means and the consequences of the act of cheating, they continue to cheat.

Each year, students seem to perfect their examination malpractice skills or come up with a new strategy for cheating. During the 2009 examinations, instances where identities were faked and students wrote whole examinations for others were reported. Sometimes parts of the same examination (written in one examination folder) are written by different students in the presence of invigilators without the latter even realising it. A number of students ask to go to the toilet at the same time and are allowed to do so. When they come back from the toilet, they exchange seats and answer certain questions as agreed between them. Then they go again to the toilet, and when they come back, they return to their respective seats. All these activities happen in the presence of invigilators who are oblivious of the exchange of seats and of the fact that the same students go to the toilet together every time. However, lecturers discover different handwritings in folders as they mark scripts. The University has introduced the Learning Management System (LMS) had to run examinations using this during the COFID-19 period for the first time during the 2019/2020 academic year. It should be interesting to find out if use of this technology will deter students from engaging in malpractice or encourage them to use be even more engaged in examination malpractice.

\section{Acknowledgements}

The study was carried out under the leadership of the University Pro-Vice Chancellor Professor Mafa Sejanamane. I thanked him for his support in approving that I use the University funds to undertake the study. I fully appreciate my former colleague Mrs. Khopotso Molise who worked with me in undertaking the study. The University 
lecturers and students who willingly participated in the study. A group of two students who captured the data made our work of analysing the data and producing the report manageable.

\section{References}

Adelakum, A. A., \& Lawal, D. A. (2008). Examination malpractice: A major challenge to public examinations in Nigeria. (The WAEC experience). Paper presented at 26th AEAA Annual conference, Accra, Ghana.

Brimble, M., \& Stevensonclarke, P. (2005). Prevalence of and Penalties for Academic Dishonesty: Perceptions of Australian Accounting Students. Unpublished research report. [Give name of university.]

Farley, F. (1991). The Type-T Personality. I Lipsett, L. \& Mitnick, L. Self-Regulatory Behaviour and Risk Taking: Causes and Consequences. Norwood, N.J.: Ablex Publication.

Nenty, H., \& Tsheko G. N. (2005). Prevalence and Determinants of Copying during Examination at University of Botswana. Unpublished paper presented during a research seminar at the University of Botswana.

Singh, A. (1984). Common sense about Examinations. India, New Delhi: Oxford University Press.

Summerson, J. B., \& Farley,J. (2009). Predicators of College Student Achievement. Retrieved from $\mathrm{http}: / /$ www.thefreelibrary.com/Predicators + of + college+student + achievement

Teferra, D. (2001). Academic Dishonesty in African Universities-Trends, Challenges, and repercussions An Ethiopian Case Study. International Journal of Educational Development, 21(2), 163-178. https://doi.org/10.1016/S0738-0593(00)00037-7

University of Botswana. (2007). University of Botswana Revised Academic Honesty Policy for Students. Unpublished policy statement.

\section{Copyrights}

Copyright for this article is retained by the author(s), with first publication rights granted to the journal.

This is an open-access article distributed under the terms and conditions of the Creative Commons Attribution license (http://creativecommons.org/licenses/by/4.0/). 